\title{
Exotic pets in Ireland: 1. Prevalence of ownership and access to veterinary services
}

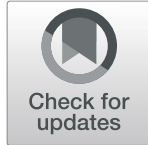

Matt Goins and Alison J. Hanlon*

\begin{abstract}
Background: There has been increasing concern expressed about the welfare of exotic pets worldwide. For the purposes of this article, an exotic pet is considered to be a non-domesticated species, where there are knowledge gaps on good practice (minimum standards of care), veterinary diagnostics and treatments. The categories of exotic pets included in this study were: small mammals $(<20 \mathrm{~kg})$, large mammals $(>20 \mathrm{~kg})$, birds, reptiles, amphibians, fish and invertebrates. Dogs, cats, rabbits, hamsters, gerbils, guinea pigs, mice, rats, and ferrets were excluded from the study. An online survey of pet owning staff at University College Dublin was conducted between July and August 2020 to provide the first empirical data for Ireland. In this pilot study (the first in this thematic series) we aim to characterise exotic pet ownership, the challenges and benefits of keeping exotic pets, and access to veterinary services from the pet owner's perspective.

Results: Using an online survey this pilot study gathered evidence from 83 domestic and 32 exotic pet owners within the staff ( $n=\sim 3600$ FTE) at University College Dublin, the largest third level institution in Ireland. The prevalence of exotic pet ownership was determined to be $34.4 \%$ of households with more than $10 \%$ of pet owning households owning only exotic pets. Fish $(n=15)$, reptiles $(n=13)$ and birds $(n=8)$ were the most common types of exotic pets. Thirty-four per cent of exotic pet owners never sought veterinary services, the most common reasons were due to lack of local veterinary specialists $(n=10)$ and good owner knowledge $(n=8)$. However identifying appropriate guidance on the animals' needs was a common challenge for exotic pet owners $(n=13)$. A reasonable monthly cost of caring for an exotic ranged from $€ 20-180$, depending on the species.

Conclusions: This pilot study contains important implications for veterinary education to support the veterinary community with providing services to the exotic pet owning community. Policy issues with exotic pet ownership also need to be considered and further research into the proposed strategies to support the health and welfare of exotic pets should be carried out such as the introduction of white lists and guidelines on responsible pet ownership.
\end{abstract}

Keywords: Exotic pet, Responsible pet ownership, Animal welfare, Veterinary services, Veterinary profession

\section{Background}

There is no generally accepted definition of an exotic pet across national or international veterinary bodies [1-3]. For example, the British Zoological Veterinary Society states that exotic pets "are strictly defined as being one of the non-domestic animals, i.e. not cat, dog, cow, horse, sheep, pig, or commercial chicken" while noting that many

\footnotetext{
*Correspondence: alison.hanlon@ucd.ie
}

School of Veterinary Medicine, University College Dublin, Dublin, Ireland would not consider pets such as rabbits or guinea pig as exotic despite including them in their definition [1] and the American Veterinary Medical Association defines exotic pets as " $a$ wide range of pet species other than domestic dogs, cats, and equids, which may be native or non-native to the United States" [2]. Differences in nomenclature are evident between Europe and North America as well. For example, 'pocket pets' are used to refer to rodents, ferrets, and rabbits as well as animals such as hedgehogs and sugar gliders [4]. For the purposes

\section{$\triangle B M C$}

(c) The Author(s). 2021 Open Access This article is licensed under a Creative Commons Attribution 4.0 International License, which permits use, sharing, adaptation, distribution and reproduction in any medium or format, as long as you give appropriate credit to the original author(s) and the source, provide a link to the Creative Commons licence, and indicate if changes were made. The images or other third party material in this article are included in the article's Creative Commons licence, unless indicated otherwise in a credit line to the material. If material is not included in the article's Creative Commons licence and your intended use is not permitted by statutory regulation or exceeds the permitted use, you will need to obtain permission directly from the copyright holder. To view a copy of this licence, visit http://creativecommons.org/licenses/by/4.0/ The Creative Commons Public Domain Dedication waiver (http://creativecommons.org/publicdomain/zero/1.0/) applies to the data made available in this article, unless otherwise stated in a credit line to the data. 
of this pilot study, an exotic pet was defined as a nondomesticated species, where there are knowledge gaps on good practice (minimum standards of care), veterinary diagnostics and treatments. Seven categories of exotic pet were included: small mammals $(<20 \mathrm{~kg})$, large mammals ( $>20 \mathrm{~kg}$ ), birds, reptiles, amphibians, fish and invertebrates. Dogs, cats, rabbits, hamsters, gerbils, guinea pigs, mice, rats, and ferrets were excluded from the study.

The prevalence of exotic pet ownership is increasing worldwide such as in the United Kingdom [5], Canada [6], Australia [7, 8], and the United States [9], as well as across Europe [9, 10], Asia [9], and South America [9]. Ownership of exotic pets is reported to be $7.1 \%$ [11], $24.1 \%$ [12], and $36 \%$ [13] of households in the UK, US, and Canada respectively, however these studies use a less restrictive definition of exotic pet than this pilot study. The prevalence of exotic pet ownership in the Republic of Ireland is undocumented. Pet choices may be influenced by portrayal of animals in the media and in the case of exotic pets, the popularity of broadcast series such as Netflix's Tiger King as well as Teenage Mutant Ninja Turtles (turtles), Finding Nemo (clownfish and blue tangs), and the Harry Potter film series (owls) [14] may reflect the zeitgeist.

There are concerns related to the welfare of exotic pets in the areas of "behavioural or interactive restriction" and "anxiety, pain, fear, or distress" [15]. For example those that relate to environment-focused activities of exploration and food acquisition, play behaviour or interactive behaviour with conspecifics [16] and those associated mainly with sensory inputs including "anxiety, fear, panic, frustration, anger, helplessness, loneliness, boredom and depression" [16]. However few studies [17] have been conducted to investigate the owners' perspective of keeping exotic pets, within the context of animal welfare, and barriers to accessing veterinary services.

The aims of this pilot study were to calculate a prevalence of exotic pet ownership within the respondent pet owning population in University College Dublin, Ireland, to characterise the availability and ease of procuring veterinary services for their exotic pets, and to gather information relating to policy proposals that could enhance the health and welfare and strengthen the human-animal bond of exotic pets.

\section{Results}

\section{Respondent demographics}

A total of 104 individuals accessed the survey. One respondent did not consent to the survey, a further eight of those that consented did not answer any questions, and two respondents did not own any pets, resulting in 93 (89.4\%) individuals completing at least the first section. This is from a pool of approximately 3600 FTE employees, which in a previous study showed a prevalence of dog ownership of $47 \%$ [18].
Respondents comprised 61 (65.6\%) domestic only pet owners, $10(10.8 \%)$ exotics only pet owners, and 22 (23.7\%) pet owners who owned both domestic and exotic pets (Table 1). On average, it took five minutes to complete the survey.

\section{Differences in pet ownership by highest household educational attainment}

The highest level of education (on the 10-level Irish National Framework of Qualification scale) in respondents' households ranged from NFQ level 3 (Junior Certificate) to NFQ Level 10 (Doctoral Degree). Differences in pet ownership were compared between households where the highest level of educational attainment corresponded to NFQ level 7 or higher $(n=85)$ and those below NFQ level $7(n=8)$. Significant differences were found in the prevalence of exotic pet ownership overall $(p=0.015)$ as well as the prevalence of ownership of small exotic mammals specifically $(p=0.036)$ with households whose highest level of educational attainment was below NFQ level 7 being more likely to own these types of pets (Fig. 1).

Differences in pet ownership by respondent housing type Respondents largely lived in houses with a garden $(n=82)$, followed by apartments $(n=5)$, houses without a garden $(n=4)$, and shared apartments $(n=2)$. The latter three categories of dwelling were pooled due to the small sample sizes to compare respondents living in dwellings

Table 1 Percentage prevalence, number and type of domestic and exotic pets owned by survey respondents in University College Dublin, Ireland

\begin{tabular}{lc}
\hline Category & Prevalence \% (n) \\
\hline Domestics (overall) & $89.24(83)$ \\
Dogs & $56.99(53)$ \\
Cats & $51.61(48)$ \\
Rabbits & $5.37(5)$ \\
Hamsters & 0.00 \\
Guinea Pigs & $5.37(5)$ \\
Gerbils & 0.00 \\
Mice/Rats & $2.15(2)$ \\
Ferrets & 0.00 \\
Exotics (overall) & $34.41(32)$ \\
Small Exotic Mammals (SEM) & $5.37(5)$ \\
Large Exotic Mammals (LEM) & $1.08(1)$ \\
Birds & $8.60(8)$ \\
Reptiles & $13.98(13)$ \\
Amphibians & 0.00 \\
Fish & $16.13(15)$ \\
Invertebrates & $5.37(5)$ \\
\hline
\end{tabular}




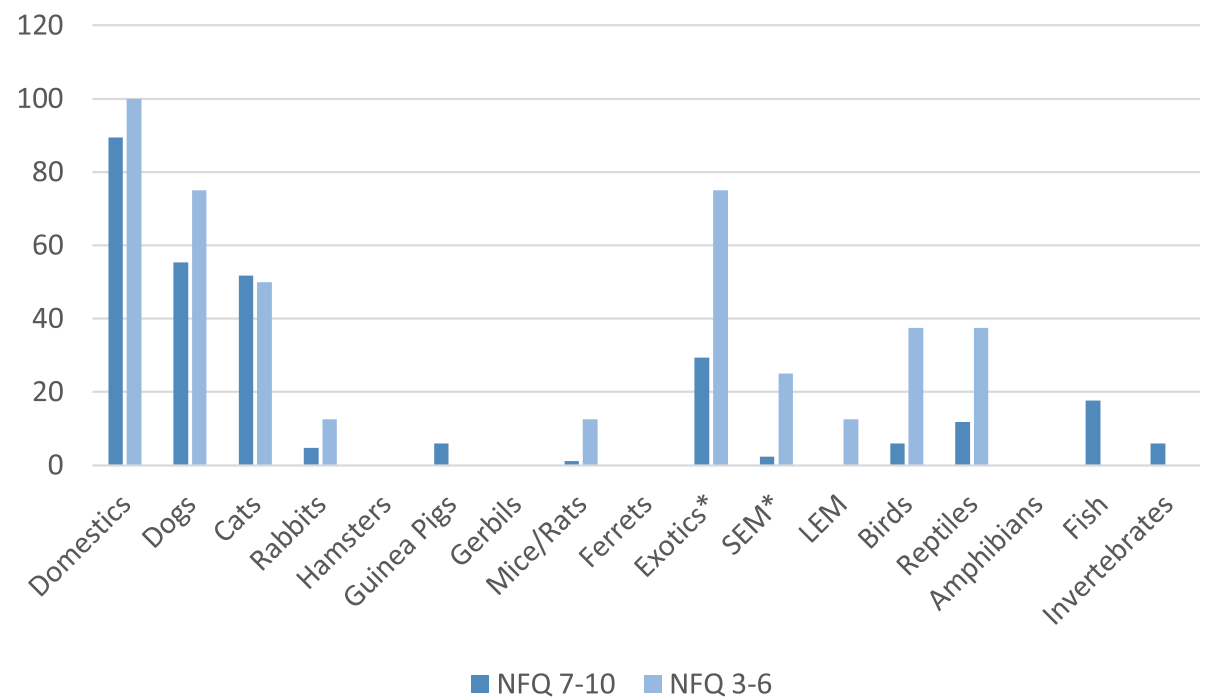

Fig. 1 Prevalence of domestic and exotic pet ownership by highest level of educational attainment per household, NFQ 7-10 ( $n=85)$ and NFQ 3-6 $(n=8)$. Significant results are denoted by an asterisk

either with $(n=82)$ or without a garden $(n=11)$. Domestic pet ownership was significantly higher in those with a garden $(92.68 \%)$ than those without a garden $(63.63 \%)$ $(p=0.016)$ (Fig. 2).

\section{Differences in pet ownership by household presence or absence of children}

The age demographic of respondent households was divided into three categories (adults (aged $>18$ ), young adults (aged 13-18), and children (aged up to 12)). Adult only households $(n=61)$ and households with children $(n=32)$ were then compared but there were no significant differences between these cohorts and categories of pet (Fig. 3).

Within households containing children, households with only young adults (aged $13-18, n=14$ ) were compared to households with only children (aged up to $12, n=13$ ). Households with only young adults were found to be significantly more likely to own dogs $(p=0.02)$ (Fig. 4).

\section{Access to veterinary services}

Of the 32 respondents that owned exotic pets, 22 $(68.75 \%)$ relayed information about their experiences in 2019 of seeking veterinary services. Eleven respondents

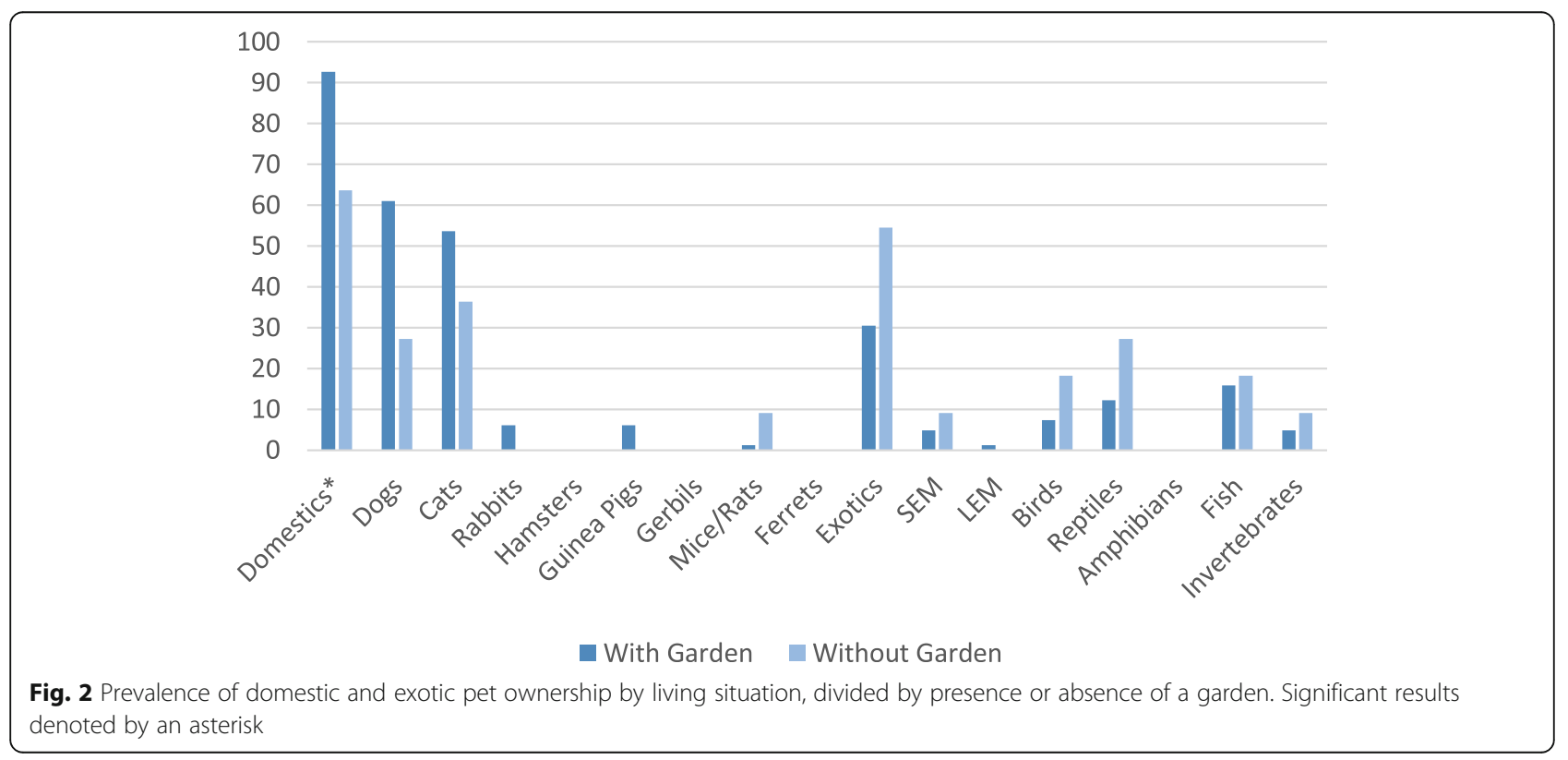




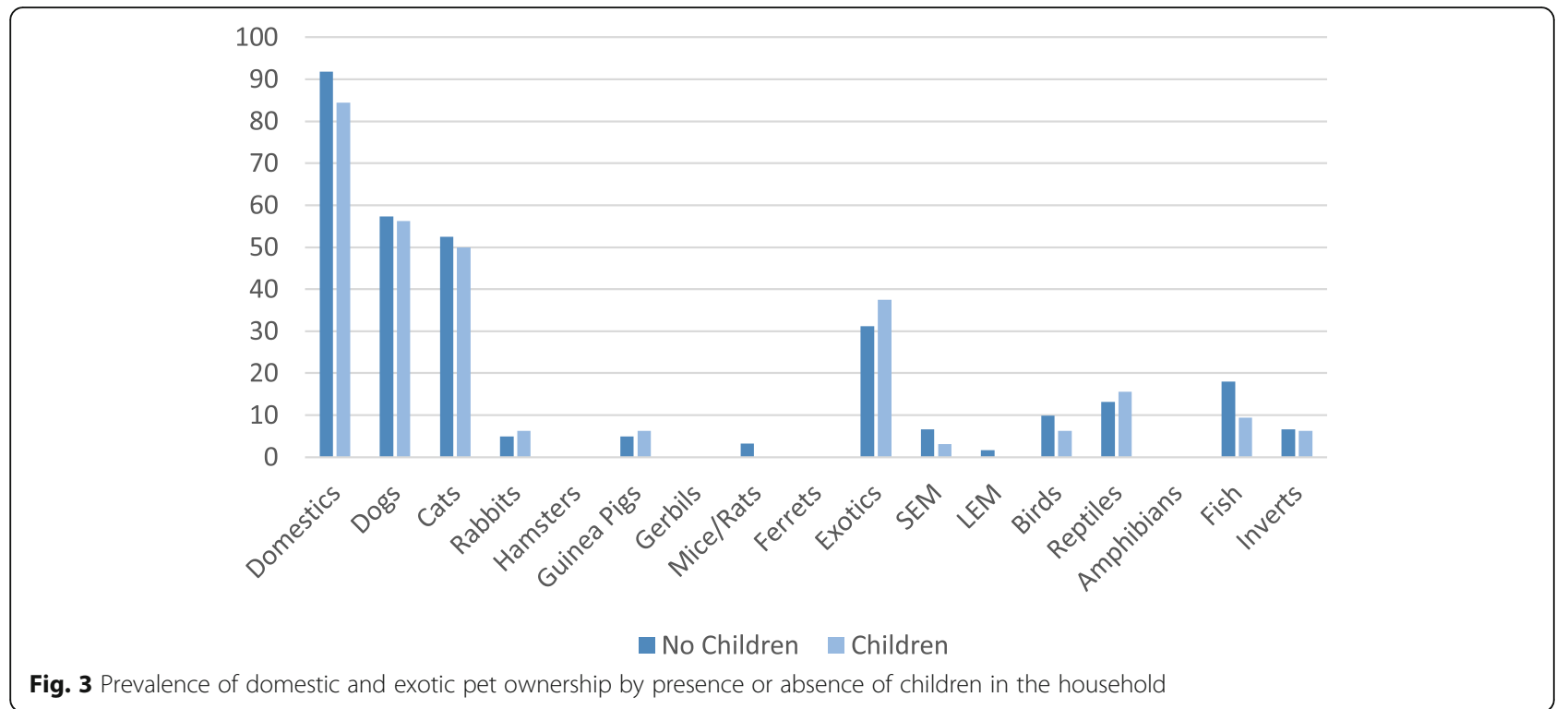

never sought veterinary services for their exotic pet(s). Of the remaining 11 respondents, four had sought veterinary services for a bird, four for a reptile, two for a small exotic mammal, and one for a fish.

Additionally, 11 (50\%) of the exotic pet owners indicated that they were first time owners of this type of exotic pet. No statistically significant difference was found between experience level (first time owners vs. more experienced owners) and likelihood to access veterinary services during 2019. For both groups, 'routine check-up' was the most common reason respondents had sought access to veterinary care.
Respondents were also asked about factors that would reduce the likelihood of accessing veterinary services. The most common responses were a lack of veterinary clinics nearby that specialised in their exotic species $(n=10,45.45 \%)$ and that the respondent possessed good knowledge of the species precluding the need to access veterinary services $(n=8,36.36 \%)$.

Benefits and challenges of exotic pet ownership

Respondents were asked to outline the main perceived benefits and challenges of exotic pet ownership. The most commonly cited benefits included that the pet is friendly,

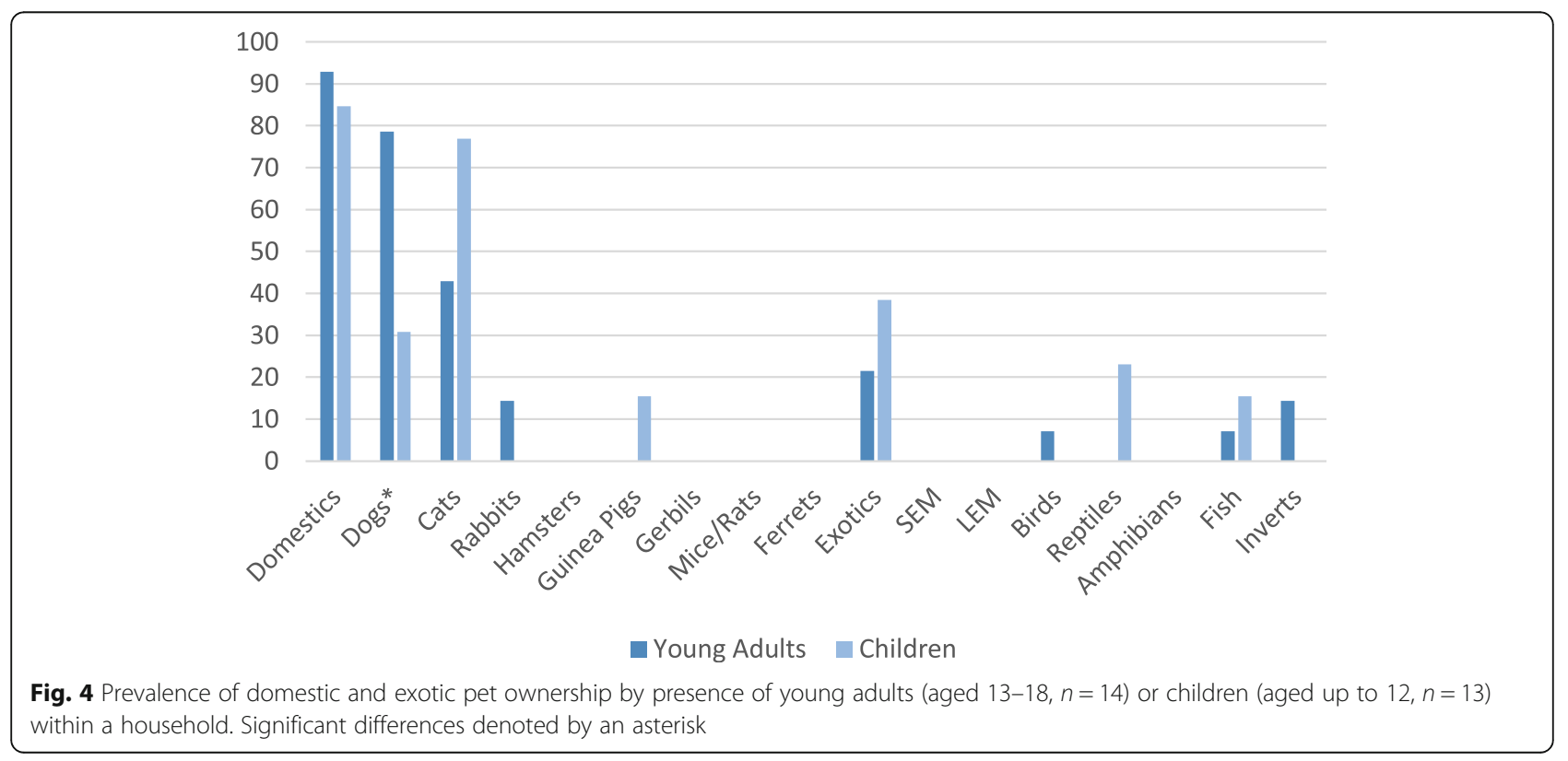


affectionate, or easy-going $(n=8)$, that the pet was calming to the owner $(n=7)$, and that exotic pet ownership offered a different view on animals $(n=6)$. Additionally, several respondents noted the increased longevity of certain types of exotic pet when compared to common domestic species as well as the idea that it was impossible for their exotic pet to experience a negative interaction with another pet in public. The most commonly cited challenge of exotic pet ownership was identifying and providing for the specific needs of each species $(n=13)$, finding a veterinary practitioner with experience in exotic pet medicine $(n=5)$, and lack of space to allow natural behaviours $(n=5)$ were also notable responses.

Respondents were also asked what a reasonable cost was per month to look after their type of exotic pet, benchmarked against the reported cost of care for a dog or cat given as approximately $€ 80$ per month [19]. Responses ranged from $€ 20-180$, with mean results of $€ 100$ per month for small exotic mammals such as an African pygmy hedgehog, €32 for birds such as parakeets and cockatiels, €43 for reptiles such as a panther chameleon and a bearded dragon, and $€ 24$ for fish.

\section{Development of strategies to support improved health and welfare of exotic pets}

The majority of respondents $(n=20,90.91 \%)$ agreed that there should be national guidelines developed to support the improved health and welfare of exotic pets. Suggested strategies included guidelines outlining the basic needs and healthcare of exotic species, licensing and testing of owner competency (e.g. knowledge of husbandry), and a register of veterinary practitioners specialising in exotic species in order to simplify searching for veterinary services.

\section{Discussion}

A key challenge of the survey was gaining access to exotic pet owners in Ireland. University College Dublin is the largest third level institution in the country with approximately 3600 FTE staff, providing a wide ranging demographic. An invitation to participate in the online survey was contained in two staff e-zines, circulated during the summer. The impact of the Covid-19 pandemic on working life is likely to have reduced engagement with the survey. Overall prevalence of pet ownership in the Republic of Ireland is unknown, though there is data supporting the prevalence of dog ownership to be $47 \%$ at University College Dublin [18]. However, overall prevalence of pet ownership in other western countries is around $41-65 \%[8,11-13]$.

\section{Prevalence of exotic pet ownership}

This pilot study demonstrates that exotic pet ownership amongst survey respondents is relatively common, considering $34.4 \%$ of pet owning households reported ownership of at least one exotic pet and more than $10 \%$ of households reported owning only exotic pets. This view is further supported by many of the exotic pet categories in this pilot study possessing higher levels of prevalence of ownership than every domestic category that was not a cat or dog. This takes on increased importance in light of the ongoing COVID-19 pandemic, which is generally accepted as having originated from a wildlife reservoir [20]. From a One Health perspective considering that $60.3 \%$ of emerging infectious diseases worldwide are zoonotic [21], with pets being a risk factor for illness caused by various pathogens [13], and the pet trade producing several high profile invasive species [9] has resulted in the FVE calling for countries to institute positive lists or 'white lists' of animals to be allowed to be kept as companion animals/ pets, such as those instituted by Belgium and the Netherlands [3].

Several demographic differences characterised pet ownership (domestic and exotic pets) including household educational attainment level, presence of a garden, and presence/absence of children in the household. For example survey respondents owning an exotic pet tended to have a lower educational attainment than domestic pet owners, ownership of domestic pets was greater in households with a garden, and ownership of dogs corresponded to households with no children. The small sample of exotic pet owners in our survey negates drawing clear conclusions about the societal demographic most likely to keep non-traditional pets.

\section{Access to veterinary services}

It is currently considered best practice for dogs and cats to access veterinary services at least once per year for an annual health check [22, 23] and according to the PDSA [19], $92 \%$ of dogs and $84 \%$ of cats in the UK are currently registered with a veterinary clinic. Comparable figures for the Republic of Ireland are unavailable. In contrast only $50 \%$ of exotic pet owners in this survey reported seeking a veterinary consultation in 2019. Whilst routine check-ups were the most common reason for owners seeking veterinary advice, barriers to accessing veterinary services included the lifespan of the animal and a perception of a lack of species-specific competency in veterinary services. Furthermore owners indicated a good knowledge of their exotic species, negating the need to visit a veterinary professional for advice. This raises potential welfare implications for exotic pets that are self-treated by their owners, as has been reported for traditional companion animals (e.g. NSAID administration in cats) $[24,25,26,27]$. A lack of guidelines on husbandry was also cited as a challenge of exotic pet ownership. 


\section{Alleviating the challenges of exotic pet ownership}

The challenges previously noted by respondents are well supported by the literature, which has found that lack of information specific to species was a particular animal welfare concern [15] as well as the difficulty in locating appropriate veterinary services [28, 29]. Additionally, respondents indicated cost-sensitivity in terms of what is "reasonable" to spend on an exotic pet in comparison to a domestic pet. This is at odds with the expectation of having access to specialist veterinarians and the additional professional costs of gaining a specialist qualification. For example, the American Board of Veterinary Practitioners requires four or more years specialty experience via internships, residencies, and other approved training programmes [30] with the applicant generally expected to be paid at a rate lower than a general practitioner and the postgraduate certificate in exotic animal practice available in the United Kingdom by Harper Adams University is expected to take two years to complete at a cost of $£ 9,495$ [31].

A good counterbalance to these challenges are a number of the proposed strategies by respondents. Guidelines of care, training and licensing of owners, and a register of qualified veterinary practitioners would help to address these concerns.

\section{Conclusions}

One third of respondents owned an exotic pet. This has implications for veterinary education to support the veterinary community with providing services to the exotic pet owning community. The development of guidelines on responsible ownership of exotic pets and codes of practice on animal care are required to address owner concerns.

Policy issues with exotic pet ownership need to be considered. Examples to be explored include development of a list of non-domesticated species that are permitted to be kept as pets such as a positive or white list as instituted by the governments of Belgium [3], the Netherlands [3], and Luxembourg [32] or implementation of a licensing systems for exotic pet owners.

Additionally, research into the proposed strategies to support the health and welfare of exotic pets are required to examine their impact on pet owners, the veterinary profession, and the welfare of the animals involved.

\section{Methods}

\section{Survey design}

An online survey was designed to characterise exotic pet ownership including the owners' perspective to the benefits and challenges of caring for exotic pets and to examine veterinary services by exotic pet owners in University College Dublin, Ireland. The survey consisted of 16 questions, divided into three sections: information about the respondent's household, exotic pet ownership, and exotic pet health.

Section one consisted of consent to participate in the pilot study and questions about the respondent's household such as the number of people living in their household, age profiles, type of dwelling (and presence or absence of a garden), highest educational level attained by a household member, the number and types of domestic companion animals owned, and whether there were any exotic pets kept in the household. This final question was used to exclude respondents that did not own exotic pets from answering sections two and three.

Section two consisted of a single question asking the respondent to enumerate the exotic pets contained within their household categorised as: small exotic mammals $(<20 \mathrm{~kg})$, large exotic mammals $(>20 \mathrm{~kg})$, birds, reptiles, amphibians, fish, and invertebrates.

Section three consisted of 11 questions asking the respondent about their most recent access to veterinary services, how many times veterinary services were accessed in 2019, the perceived benefits and challenges of owning that type of exotic pet, and owner attitudes and suggestions with regard to various policy proposals around exotic pet ownership.

The survey was published online using SurveyMonkey ${ }^{\circ}$ and was open for responses from 15 July to 5 August 2020. An invitation to complete the survey was distributed by University College Dublin in their staff e-zine on 15 July and 29 July 2020. The study population of staff at University College Dublin comprised approximately 3600 FTE Employees, a diversity of roles (academic, technical, support and administration) and levels of educational attainment. A copy of the survey can be found in the Supplementary Materials.

\section{Data handling and analysis}

Data were exported from SurveyMonkey into Microsoft Excel (2013). R version 3.6.1 and R Studio version 1.2.1335 were used for data cleaning and transformation, data visualisation, generating descriptive statistics, and for all statistical analyses. Microsoft Excel (2013) was also used to generate graphs. To test for statistically significant differences in the frequencies of responses between independent cohorts, a Pearson's Chi-Squared test or Fisher's exact test was conducted depending on sample size. Comparisons were made between the responses of respondents living in houses with gardens and those without gardens, respondents whose household highest educational attainment fell between NFQ Level 3 and 6 and those whose household highest educational attainment fell between NFQ Level 7 and 10, and households that included children and those whose households contained only adults. The significance threshold for statistical analyses was $p<0.05$. 


\section{Abbreviations}

FTE: Full Time Equivalent; NFQ: National Framework Qualification

\section{Supplementary Information}

The online version contains supplementary material available at https://doi. org/10.1186/s13620-021-00190-6.

Additional file 1. Exotic pet owners survey

\section{Acknowledgements}

We appreciate the valuable feedback provided by Claire Greene, MVB MRCVS GPCert(ExAP) of Bairbre O'Malley Veterinary Hospital (Co Wicklow) and Dee Collins, MVB MRCVS GPCert(ExAP) of Paws A While Veterinary Clinic (Co Meath) on the draft survey, Athina Kranidi of the Centre for Support and Training in Analysis and Research (CSTAR), and the support of Mark Simpson for his help in circulating the survey.

\section{Authors' contributions}

Conceptualisation, MG and $\mathrm{AJH}$; methodology, MG and AJH; software, MG; validation, $\mathrm{MG}$ and $\mathrm{AJH}$; formal analysis, MG; data curation, MG; writing - original draft preparation, MG; writing - review and editing, $M G$ and $A J H$; visualisation, MG; supervision, AJH. The authors read and approved the final manuscript.

\section{Funding}

This pilot study was supported by a UCD Summer Student Research Award.

\section{Availability of data and materials}

The data generated during this study are available from the corresponding author on reasonable request.

\section{Declarations}

\section{Ethics approval and consent to participate}

The survey was considered to be low risk according to the guidelines of the Human Research Ethics Committee at University College Dublin and was awarded exemption from full ethical approval (LS-E-20-80-Hanlon).

\section{Consent for publication}

Not applicable.

\section{Competing interest}

The authors declare no competing interest.

Received: 11 December 2020 Accepted: 13 April 2021

Published online: 26 May 2021

\section{References}

1. British Zoological Veterinary Society FAQs on exotic animals. [(accessed on 28 August 2020)]; Available online: https://www.bvzs.org/images/uploads/ BVZS_FAQs_on_exotic_animals.pdf.

2. American Veterinary Medical Association Ownership. and or possession and appropriate disposition of wild and exotic pet species and their hybrids. [(accessed on 28 August 2020)] Available online: https://www.avma.org/ resources-tools/avma-policies/ownership-and-or-possession-and-appropria te-disposition-wild-and-exotic-pet-species-or.

3. Federation of Veterinarians of Europe Regulation. of keeping animals as companion animals through the establishment of lists. [(accessed on 28 August 2020)] Available online: https://www.fve.org/cms/wp-content/uploa ds/006_fve_position_on_positive_lists_of_exotic_species_final.pdf.

4. Stickney M Surgical Techniques in Exotics and Pocket Pets. 2019 Veterinary Technicians Conference: Conference Proceedings, 2019 Jun 21-23; College Station: Texas A\&M Office of Veterinary Continuing Education; 2019. 79-83p.

5. Stanford M. Keeping exotic pets. Vet Rec. 2013;173(23):586. https://doi.org. ucd.idm.oclc.org/10.1136/vr.f7408.

6. Kieswetter $\mathrm{S}$. The motivations behind obtaining exotic pets: a discussion paper. East York (CA): Zoocheck inc; 2017; 13p.

7. Chaseling S. Pet populations in Australia. Dogs increasing and cats decreasing - why is it so? In: Murry R, ed. Proceedings of the 10th Urban Animal Management Conference; 2001 Aug; Melbourne, Australia [conference proceedings on the Internet]. Melbourn (AU): AVA Ltd; 2001. [cited 2020 Aug 31]. Available at: http://aiam.org.au/resources/Documents/2 001 \%20UAM/PUB_Pro01_SusieChasling.pdf.

8. Australian Companion Animal Council. Contribution to the pet care industry of the Australian economy. 7th ed. Victoria: Rockwell Communications; 2010. 81p.

9. Lockwood JL, Welbourne DJ, Romagosa CM, Cassey P, Mandrak NE, Strecker A, et al. When pets become pests: the role of the exotic pet trade in producing invasive vertebrate animals. Front Ecol Environ. 2019:17(6):323-30. https://doi.org.ucd.idm.oclc.org/10.1002/fee.2059.

10. British Veterinary Association. Plans for a review of exotic pet trade in Scotland. Vet Rec. 2015;176:187. https://doi.org.ucd.idm.oclc.org/10.1136/vr.h898.

11. Pet Food Manufacturers' Association Pet Population. 2020. [(accessed 31 August 2020)]; Available online: https://www.pfma.org.uk/pet-population-2020.

12. American Pet Products Association Pet Industry Market Size \& Ownership Statistics. 2020. [(accessed 31 August 2020)] Available online: https://www.a mericanpetproducts.org/press_industrytrends.asp.

13. Stull JW, Peregrine S, Sargeant JM, Weese JS. Pet husbandry and infection control practices related to zoonotic disease risks in Ontario, Canada. BMC Public Health. 2013;13:520. https://doi.org/10.1186/1471-2458-13-520.

14. Megias DA, Anderson SC, Smith RJ, Verissimo D. Investigating the impact of media on demand for wildlife: A case study of Harry Potter and the UK trade in owls. PLOS One. 2017;12(10). https://doi.org/10.1371/journal.pone.0182368.

15. Bush ER, Baker SE, MacDonald DW. Global trade in exotic pets 2006-2012. Conserv Biol. 2014;28(3):663-76. http://www.jstor.org/stable/24480328.

16. Mellor DJ. Updating Animal Welfare Thinking: Moving beyond the "Five Freedoms" towards "A life worth living". Animals. 2016;6:21.

17. Lennox AM. Exotic pet mammals: current state of exotic mammal practice. In: Proceedings of Association of Avian Veterinarians. 2006.

18. PAW PDSA Animal Wellbeing Report. 2019. [(accessed 31 August 2020)]; Available online: https://www.pdsa.org.uk/media/7420/2019-paw-report_ downloadable.pdf.

19. The Irish Society for the Prevention of Cruelty to Animals. A Survey on Perceptions of Responsible Dog Ownership in Ireland [pamphlet]. Dublin: The Irish Society for the Prevention of Cruelty to Animals; 2016. [(accessed 20 November 2020)]; Available online: https://www.ispca.ie/images/pages/ISPCA_A_ Survey_on_Perceptions_of_Responsible_Dog_Ownership_in_Ireland.pdf.

20. Shereen MA, Khan S, Kazmi A, Bashir N, Siddique R. COVID-19 infection: Origin, transmission, and characteristics of human coronaviruses. J Adv Res. 2020;24:91-8.

21. Day MJ. Vaccination of dogs and cats: no longer so controversial? Vet Rec. 2011;168:480-2p.

22. Day MJ, Horzinek MC, Schultz RD. WSAVA Guidelines for the vaccination of dogs and cats. J Small Anim Pract. 2010;51(6):1-32p.

23. Finco DC, Duncan JR, Scall WD, Prasse KW. Acetaminophen toxicosis in the cat. J Am Vet Med Assoc. 1975;166(5):469-72.

24. Avizeh R, Najafzadeh H, Razijalali M, Shirali S. Evaluation of prophylactic and therapeutic effects of silymarin and $\mathrm{N}$-acetylcysteine in acetaminopheninduced hepatotoxicity in cats. J Vet Pharmacol Ther. 2010;33(1):95-9.

25. Fitzgerald KT, Bronstein AC, Flood AA. "Over-The-Counter" Drug Toxicities in Companion Animals. Clin Tech Small Anima Pract. 2006:21(4):215-26.

26. Merola V, Dunayer E. The 10 most common toxicoses in cats. Vet Med. 2006;101(6):339-42.

27. Whitehead ML. Factors contributing to poor welfare of pet reptiles. Testudo. 2018;8(5):47-61.

28. Warwick C. The morality of the reptile "pet" trade. J Anim Ethics. 2014;4(1):74-94p.

29. American Board of Veterinary Practitioners. ABVP Applicant Handbook. Gainesville: American Board of Veterinary Practitioners; 2019. Available online: https://abvp.com/wp-content/uploads/2019/03/01-Applicant-Ha ndbook.pdf. Accessed 20 Nov 2020.

30. Improve International [Internet]. United Kingdom: Improve International Ltd.; c2020 [cited 2020 Nov 20]. Available from: https://www.improveinternationa I.com/uk/course/pgc-gpcert-exotic-animal-practice/.

31. Grand-Ducal Regulation of November 16, 2018 fixing the lists of authorized animals and the specific procedures for application for authorization to keep. (Grand Duchy of Luxembourg).

32. Jones KE, Patel NG, Levy MA, Storeygard A, Balk D, Gittleman JL, Daszak P. Global trends in emerging infectious diseases. Nature. 2008;451:990-3p.

\section{Publisher's Note}

Springer Nature remains neutral with regard to jurisdictional claims in published maps and institutional affiliations. 